\title{
Entre rezas, lágrimas, suor, menstruação e chulé: o futebol feminino em foco
}

Mariane da Silva Pisani

Universidade de Sáo Paulo, Sáo Paulo, Sáo Paulo, Brasil

DOI 10.11606/issn.2316-9133.v24i24p338-347

Existem muitas produções bibliográficas e audiovisuais que mostram a inserção e a consolidação do futebol - como esporte de preferência nacional - no Brasil. A grande maioria delas reconstitui a história social desse esporte sob a perspectiva dos homens, seja na qualidade de jogadores, de torcedores e/ou daqueles que escreveram e produziram a memória da modalidade. Em breve levantamento sobre essas produções, veremos que descrevem como o aparecimento do futebol no Brasil - no ano de 1884 foi associado a uma prática de lazer essencialmente destinada aos homens brancos da elite do país. Posteriormente, algumas produçóes mostraram que o futebol passou por uma popularização a partir do ano de 1930, profissionalizando-se e permitindo assim que outros homens, negros e pobres, pudessem adentrar os campos e os estádios como jogadores (agora remunerados) e como torcedores. Notamos também que houve uma grande discussáo e problematizaçáo sobre o lugar que o futebol ocupou no imaginário social durante o período militar brasileiro. Fica evidente a partir dessas produçóes que a virilidade, a competitividade e as características agonísticas da modalidade ainda hoje associam-se intimamente a um ideal de identidade masculina brasileira.

As mulheres sempre foram colocadas à margem na produção histórica sobre o futebol brasileiro. Até o ano de 1920, quando apareciam nas crônicas esportivas e colunas sociais, eram retratadas como meras espectadoras que traziam beleza e charme para as arquibancadas. No ano de 1921, os jornais do país noticiaram - não sem algum assombro - a primeira partida de futebol disputada por mulheres. À época elas foram chamadas de audaciosas e intrépidas, e a partida, por sua vez, foi motivo de chacota e desconfiança do grande público brasileiro.

No ano de 1941, sob o pretexto de preservar a saúde reprodutiva dessas mulheres, o Conselho Nacional de Desportos decretou que alguns esportes não seriam compatíveis com a natureza feminina. Acreditava-se que a prática do futebol colocaria em risco a integridade física das mulheres brasileiras: uma forte pancada no baixo ventre poderia torná-las inférteis, 
comprometendo a maternidade. Dessa forma, até 1979, as mulheres foram proibidas por lei de jogar futebol .

No ano de 2001, a Federaçáo Paulista de Futebol (FPF) estabeleceu que, para que uma atleta pudesse participar de campeonatos, precisaria apresentar signos de feminilidade: cabelos compridos, corpo mais delicado e com curvas, uniformes mais curtos e justos. Em entrevista de jornal concedida na época, a jogadora Cristiane Silva, medalhista de prata na Olimpíada de Atenas, afirma ser favorável a um modelo de uniforme intermediário, ou seja: nem tão grande, mas também não tão justo. Contudo, segundo a atleta, ela usaria um modelo mais cavado se o clube ou patrocinador mandasse, pois "é melhor jogar assim do que não jogar".

No ano de 2004, depois que a Seleção Brasileira de Futebol Feminino conquistou a medalha de prata nas Olimpíadas de Atenas, algumas reportagens jornalísticas questionaram o preconceito que ronda a modalidade. Este relacionava-se, sobretudo, ao desinteresse popular por conta da suposta homossexualidade das atletas. Da mesma forma, como no começo do século XX, as poucas reportagens e entrevistas realizadas com atletas da modalidade continuam evidenciando o charme e a beleza da jogadora brasileira em detrimento de sua competência profissional e qualidade técnica.

Por fim, no ano de 2015, no mês de julho, 24 países participaram da VII Copa do Mundo de Futebol Feminino, sediada no Canadá. No Brasil, desde de janeiro daquele ano, a Seleçáo Feminina se preparou para a competição, buscando a conquista do título ainda inédito no país.

Sendo o futebol uma modalidade direcionada e compreendida a partir da perspectiva dos homens, os discursos sobre a presença das mulheres nesse espaço avançam, quase sempre, em três direçóes: a) descrevem-nas como seres naturalmente dóceis e frágeis, voltados para a maternidade e possuidores de aspectos essencialmente femininos, logo náo pertencentes ao mundo futebolístico; b) colocam em dúvida a sexualidade da mulher atleta sob argumentos desqualificantes e homofóbicos; c) instauram medidas arbitrárias que condicionam e restringem, a partir de um discurso fetichista e sexista, a presença delas no âmbito esportivo. Apesar das tentativas de exclusão, das restriçốes e dos obstáculos enfrentados por elas ao longo dos últimos anos, o futebol feminino pode mostrar-se como um espaço de autonomia e liberdade, propiciando o empoderamento das mulheres.

As fotos que trago são produtos do trabalho de campo para a tese de doutorado que realizo no Programa de Pós-Graduação em Antropologia Social, na Universidade de São Paulo. O objetivo é mostrar um pouco do cotidiano dessas mulheres: quem são e de onde vêm? Quais são seus sonhos e perspectivas? Elas conseguem fazer do futebol seu meio de vida? Dessa 
forma, a narrativa fotográfica é construída a partir do convívio mais intenso com uma equipe de futebol feminino da capital: a Associação Atlética Pró-Esporte (ASAPE), criada e comandada pela técnica Ita Maia Reis. As fotos foram realizadas ao longo de noves meses (de novembro de 2013 a agosto de 2014) e mostram como é um dia de jogo na vida de jogadoras de futebol.

autora Mariane da Silva Pisani

Bacharel em Ciências Sociais pela Universidade Federal de Santa Catarina. Realizou mestrado em Antropologia Social na Universidade Federal de Santa Catarina. Atualmente é aluna de doutorado em Antropologia Social na Universidade de São Paulo.

Recebido em 07/04/2015 Aceito para publicaçáo em 13/10/2015 

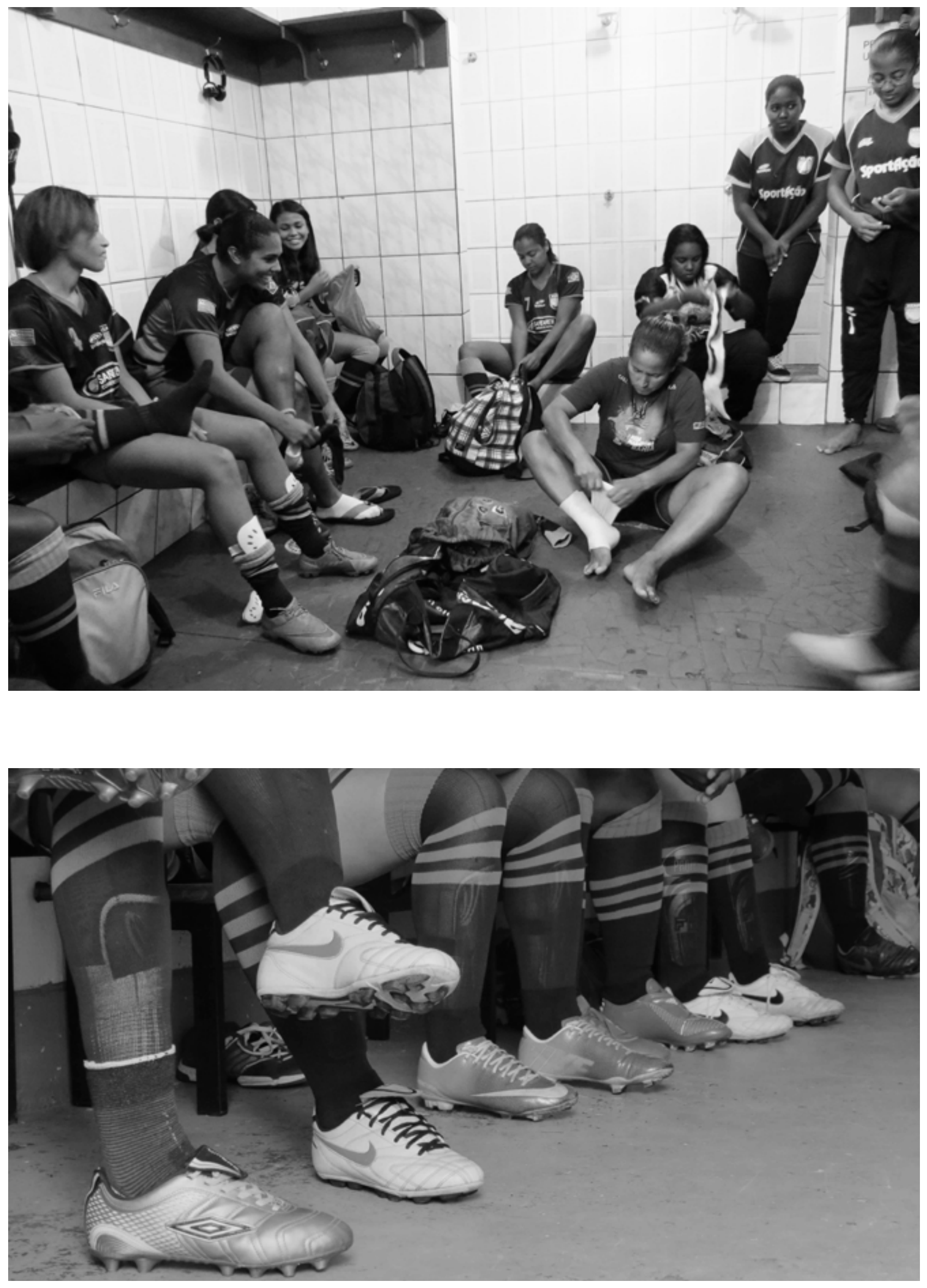
342 | Mariane da Silva Pisani
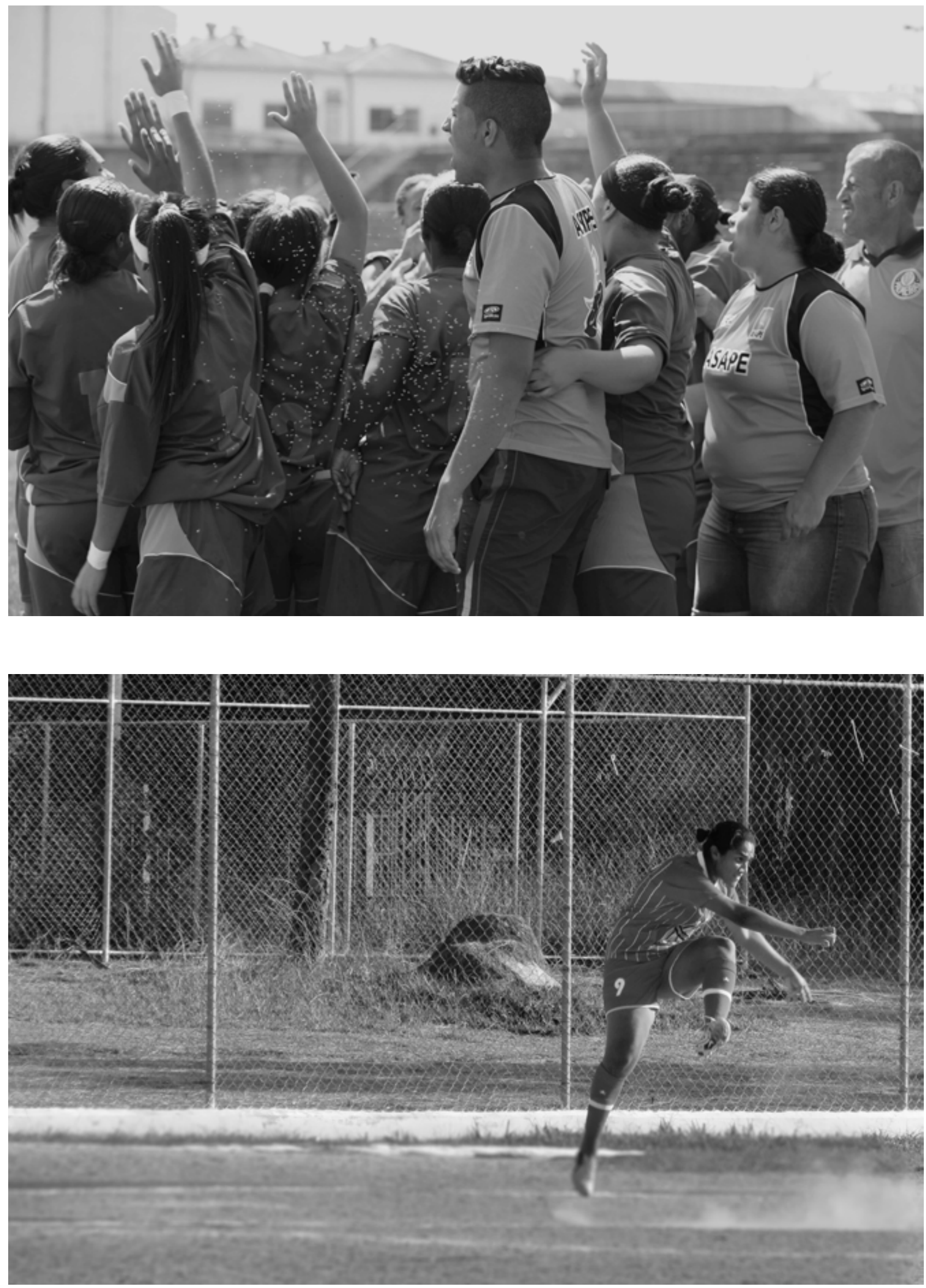
ENTRE REZAS, LÁGRIMAS, SUOR, MENSTRUAÇÃo E CHULÉ | 343

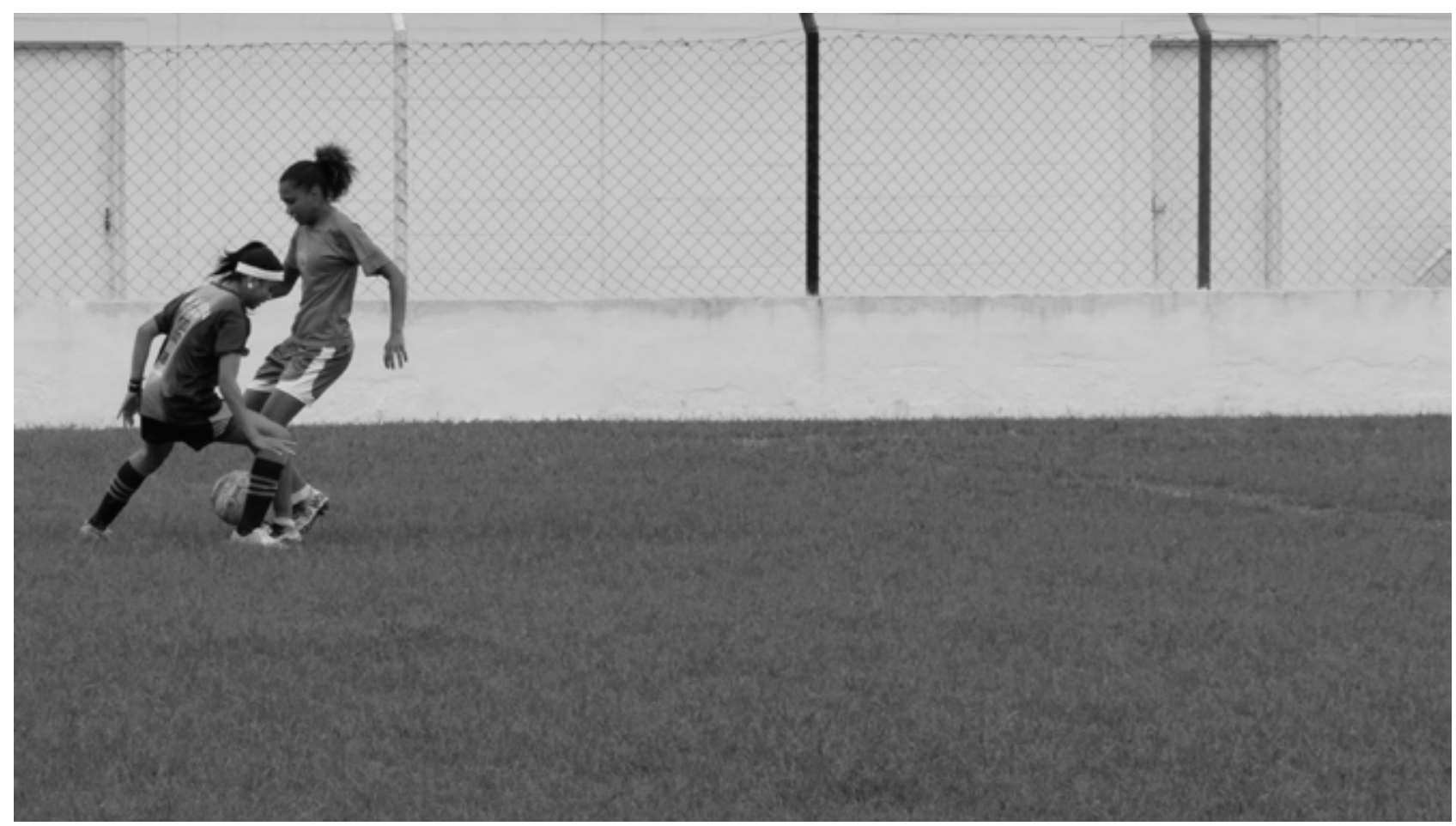




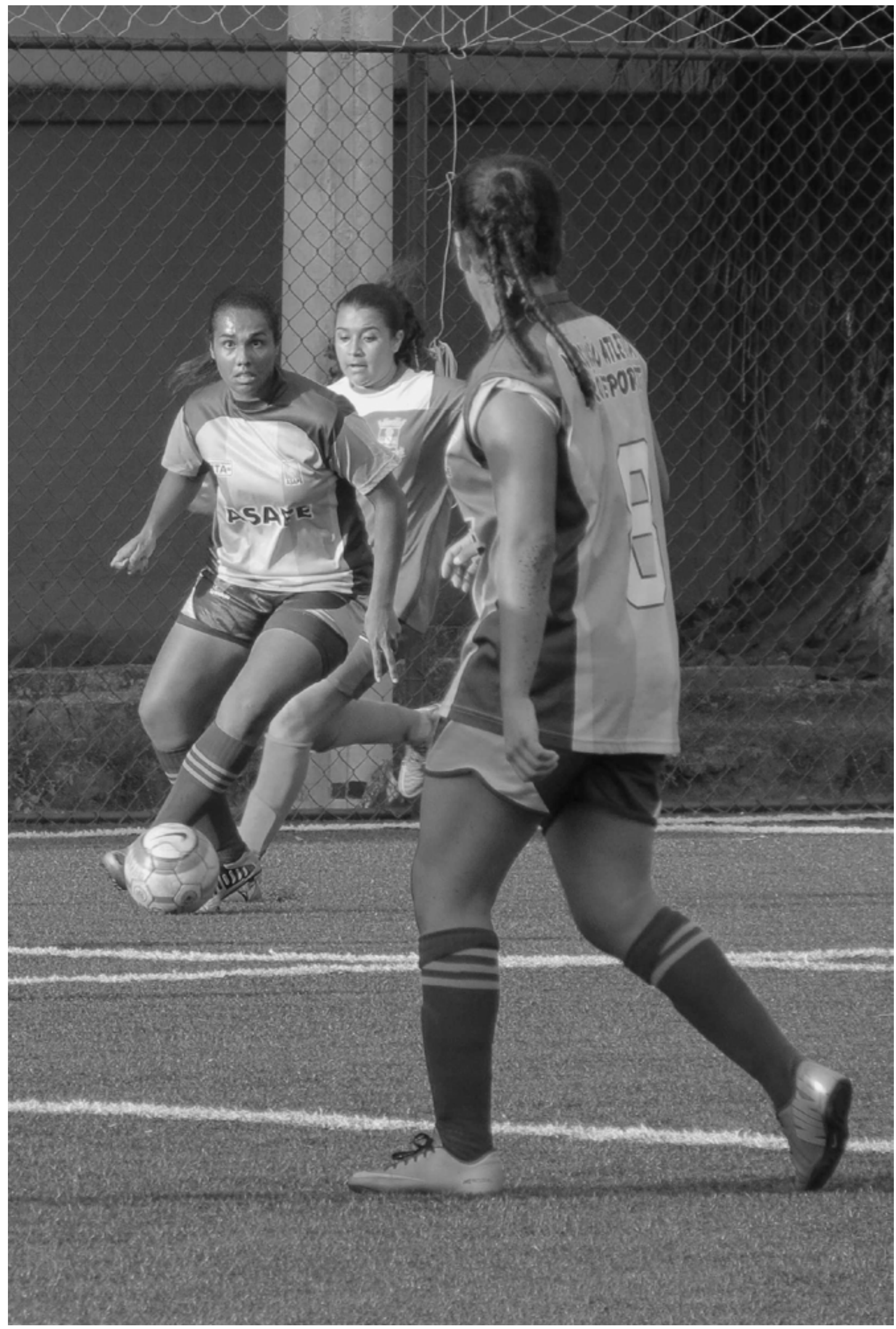


ENTRE REZAS, LÁGRIMAS, SUOR, MENSTRUAÇÃo E CHULÉ | 345
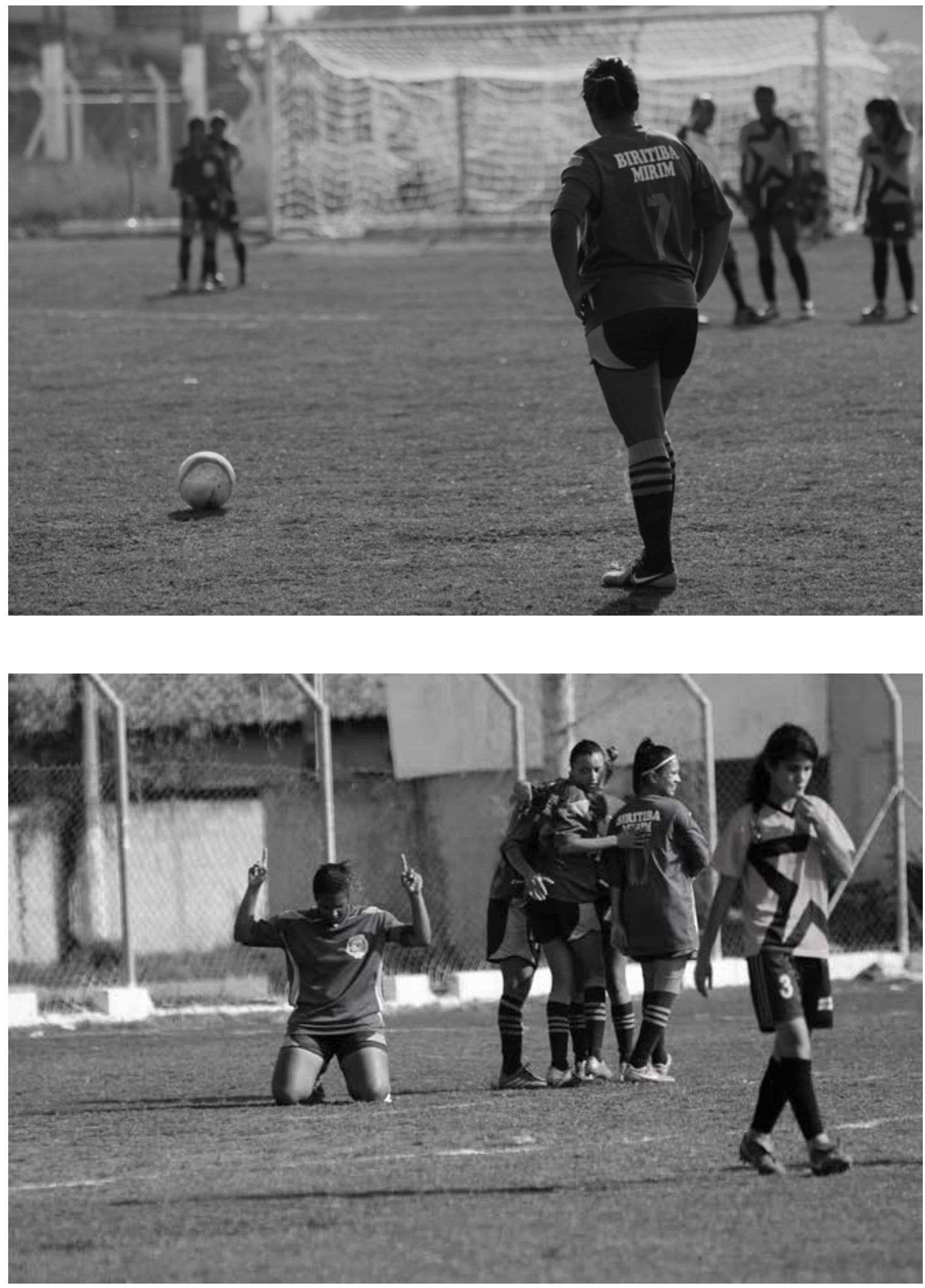
346 | Mariane da Silva Pisani
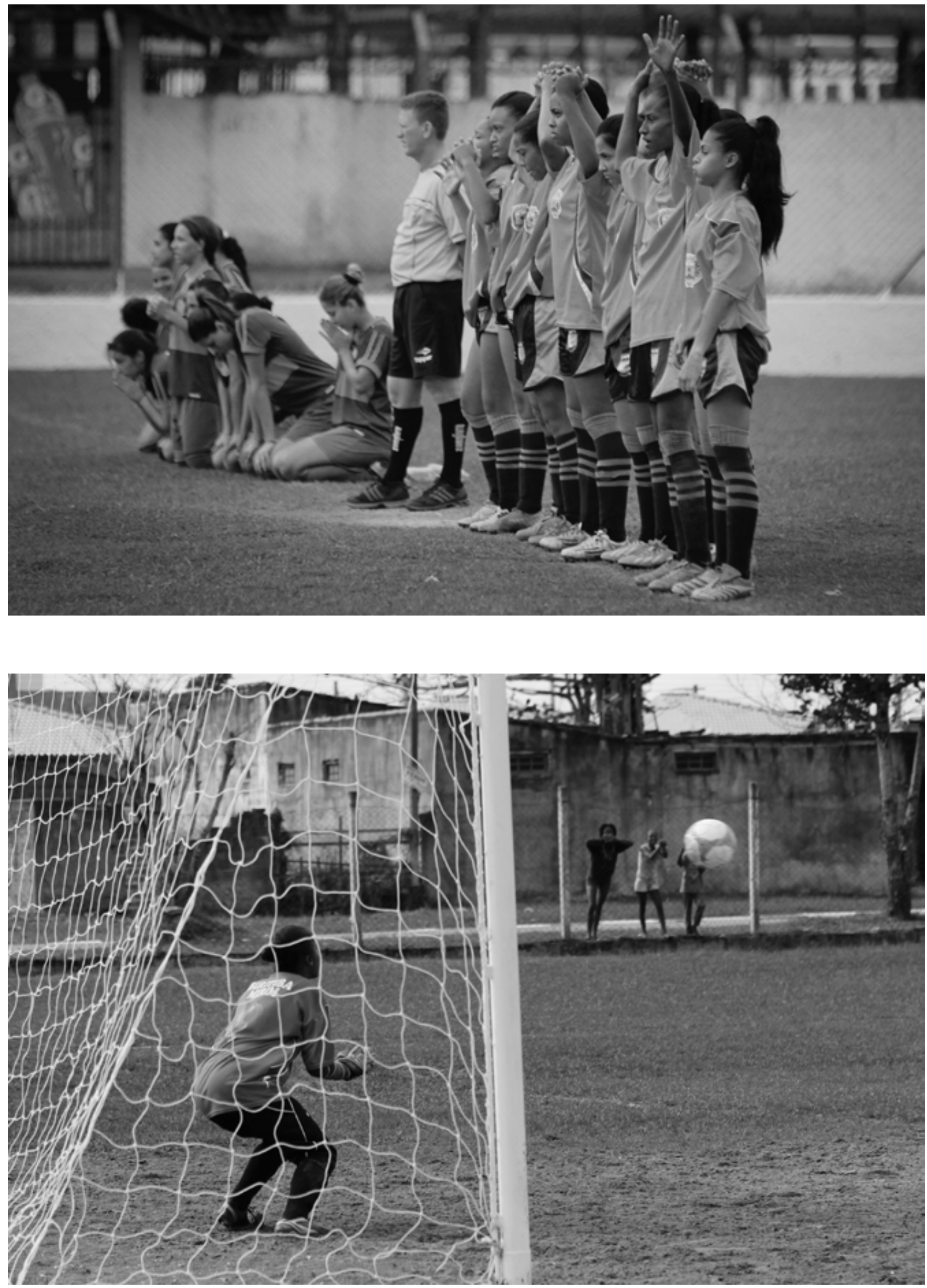
ENTRE REZAS, LÁGRIMAS, SUOR, MENSTRUAÇÃo E CHULÉ | 347

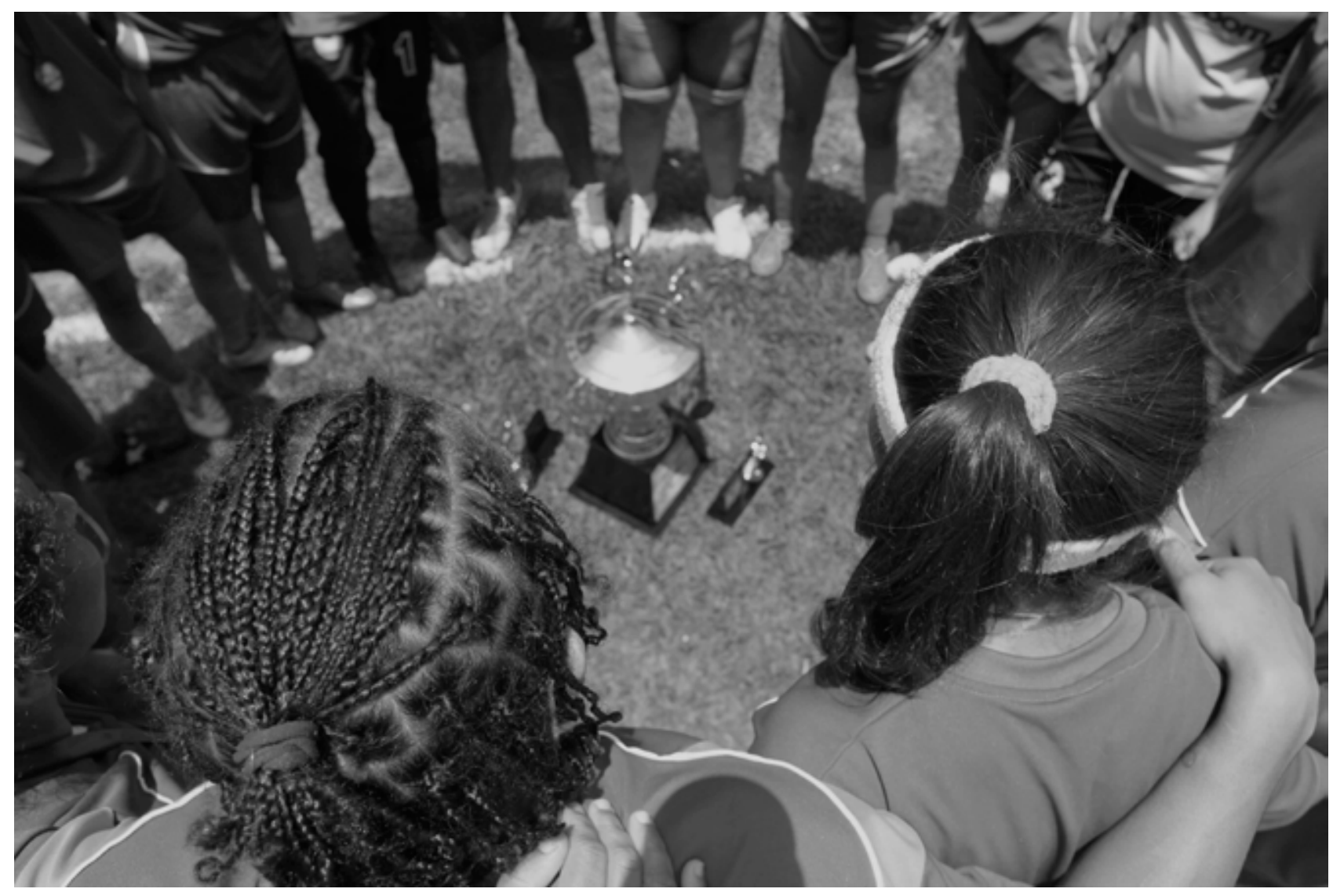

